\title{
Sauberkeit und Protektionismus
}

\author{
Die USA sind ein wichtiger Exportmarkt für Reinigungsanlagen Made in Germany. \\ Mit dem neuen US-amerikanischen Präsidenten könnte sich das ändern.
}

In den USA ist die wässrige Reinigung als Standardtechnologie etabliert, wobei häufig einfache Band- und Spritzreinigungsanlagen ohne Medienaufbereitung im Einsatz sind. Damit wird bei vergleichsweise hohen Betriebskosten ein mehr oder weniger ausreichendes Reinigungsergebnis erzielt. Sind anspruchsvollere Reinigungsaufgaben zu lösen, erfolgt dies üblicherweise mit einer Ultraschallreinigung in Reihentauchanlagen.

Im Bereich der Lösemittelreinigung sind geschlossene Kammeranlagen mit integrierter Destillation bisher eher die Ausnahme. Deutlich häufiger werden so genannte Open-Top-Anlagen für die Dampfentfettung und Reinigung betrieben. Sie führen neben hohen Verbräuchen zu einer Gefährdung von Mitarbeitern und Umwelt. Die Environmental Protection Agency (EPA) hat deshalb ein Verfahren zur Evaluierung der Risiken durch zehn chemische Substanzen eingeleitet. Dazu zählen Trichlorethylen und Perchlorethylen.

\section{Bewusstsein für Sauberkeit wächst}

Bei zahlreichen Anwendern hat die industrielle Teilereinigung nach wie vor keinen sonderlich hohen Stellenwert und das Wissen darum ist nicht ausgeprägt. Es gibt jedoch eine zunehmende Zahl von Anwendungen, beispielsweise aus der Automobil- und Zulieferindustrie, Luftfahrt, Medizintechnik, Konsumgüterindustrie, Hydraulik sowie Elektronik, in denen hohe Anforderungen an die Sauberkeit der Teile zu erfüllen sind. Dies sind klassische Aufgabenstellungen, bei denen sich US-amerikanische Firmen sowie Niederlassungen international operierender Unternehmen häufig für Reinigungstechnik aus Deutschland beziehungsweise Europa entscheiden.

Die nachweisbar erreichbare technische Sauberkeit, hohe Prozesssicherheit, die Zuverlässigkeit der Anlagen und das gute Image des deutschen Anlagenbaus spielen dabei eine ebenso ausschlaggebende Rolle wie Referenzen im jeweiligen Marktseg- ment. Positiv wirkt sich momentan auch der gegenüber dem US-Dollar schwache Euro positiv aus.

\section{Protektionismus führt zu Verunsicherung}

Die Ankündigung des neuen amerikanischen Präsidenten, Handelsschranken aufzubauen und Einfuhrzölle zu erheben, macht deutschen Anlagenbauern derzeit noch keine allzu großen Sorgen. Die USamerikanische Wirtschaft sei weltweit $\mathrm{zu}$ verflochten, um dieser damit nicht auch zu schaden, lautet die Einschätzung der Hersteller.

Allerdings sind sie sich auch einig darüber, dass die Auswirkungen momentan noch nicht definitiv abschätzbar sind. So könnte es durchaus zu Verunsicherungen und damit auch zu Verschiebungen von Investitionen oder $\mathrm{zu}$ einer lokalen Beschaffung kommen. Profitieren davon könnten Hersteller mit eigenen Niederlassungen in den USA. //

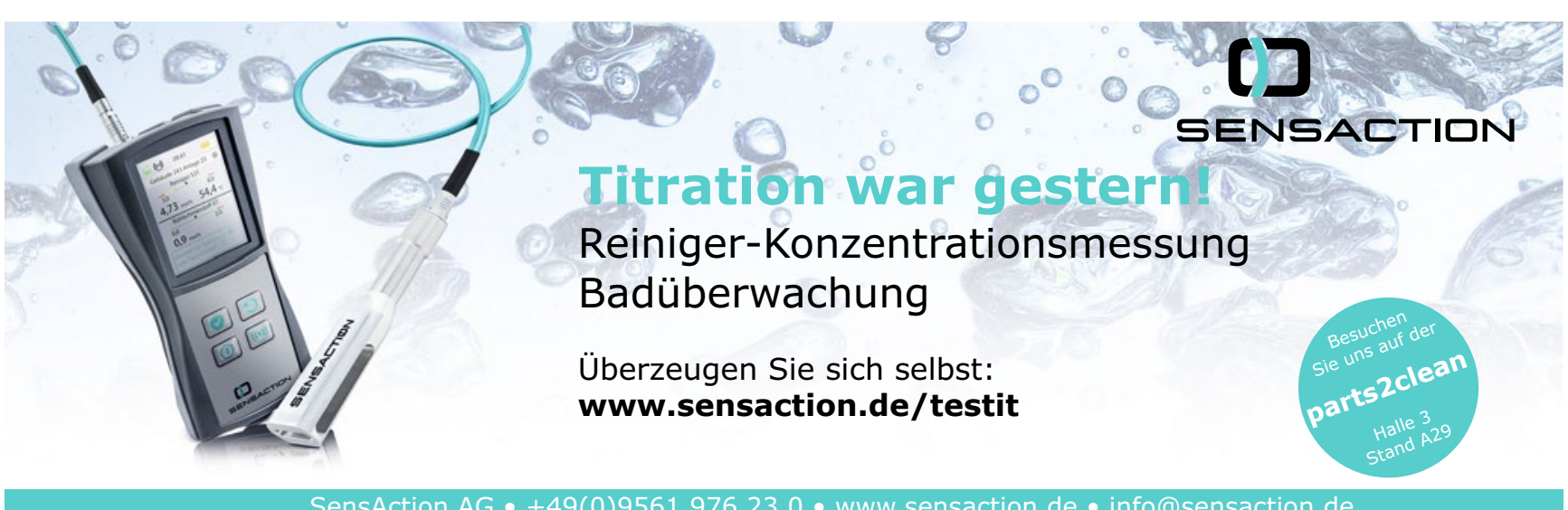

